\title{
Produção em série? A subjetividade do professor universitário no cenário de industrialização acadêmica ${ }^{1}$
}

\author{
Ana Helena Ribeiro Garcia de Paiva Lopes \\ Universidade Federal de São Carlos (UFSCar), São Carlos - SP, Brasil. \\ aninhargplopes@hotmail.com
}

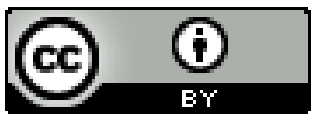

Educação: teoria e prática, Rio Claro, SP, Brasil - elSSN: 1981-8106

Está licenciada sob Licença Creative Common

\begin{abstract}
Resumo
Em uma sociedade capitalista na qual impera a competitividade e a produção desmedida, deveria ser a universidade espaço de reflexão e crítica. Contudo, parece ter também a academia se rendido às esteiras da produção em série, fazendo dos professores servos de publicações, defesas, apresentações de trabalho, organização de seminários etc. Diante de tal cenário, faz sentido supor que a subjetividade docente, em um contexto de aprisionamento da criatividade e da intencionalidade própria do professor, se faz ausente. Como uma das possíveis consequências desse processo de enrijecimento do eu, tem-se precarização do trabalho docente com a possibilidade de adoecimento deste. Todavia, é possível que o elemento vivo do humano seja resgatado e que, por esse motivo, a subjetividade docente seja construída de modo a exercitar o trabalho criativo. Este artigo tem como objetivo discutir de que modo se dá o árduo, mas possível, processo de construção da subjetividade do professor universitário em tempos de indústria acadêmica.
\end{abstract}

Palavras-chave: Trabalho Docente. Universidade. Subjetividade. Sociabilidade.

\section{Production series? The subjectivity of the professor in the backdrop of industrialization academic}

\begin{abstract}
In a capitalist society in which reigns competitiveness and excessive production, the university should be space for reflection and critique. However, it also seems to have surrendered to the mats of mass production, making teachers servants publications,

\footnotetext{
${ }^{1}$ Este artigo é resultante da disciplina optativa do Programa de Pós-Graduação em Educação (PPGE) da Universidade Federal de São Carlos (UFSCar), Trabalho do Professor, ministrada pelo Prof. Dr. Eduardo Pinto e Silva durante o primeiro semestre letivo de 2012.
} 
defenses, paper presentations, seminars etc. Faced with this scenario, it makes sense to assume that the teacher subjectivity, in a context of imprisonment of creativity and intentionality own teacher, becomes absent. As one of the possible consequences of this process of hardening of the self, has casualization of teaching with the possibility of this disease. However, it is possible that the human element alive is redeemed and that, therefore, the teacher subjectivity is constructed to exercise your creative work. This article aims to discuss how it takes the hard, but possible, construction of subjectivity university professor in times of academic industry.

Keywords: Teaching. University. Subjectivity. Sociability.

\section{¿Producción en serie? La subjetividad del profesor universitario en el escenario de industrialización académica}

\section{Resumen}

En una sociedad capitalista en la que impera la competitividad y la producción desmedida, debería ser la universidad espacio de reflexión y crítica. Con todo, también parece que la academia se ha rendido a las cintas de la producción en serie, haciendo de los profesores siervos de publicaciones, defensas, presentaciones de trabajo, organización de seminarios etc. Delante de tal escenario, tiene sentido suponer que la subjetividad docente, en un contexto de aprisionamiento de la creatividad y de la intencionalidad propia del profesor, se hace ausente. Como una de las posibles consecuencias de este proceso del fortalecimiento del yo, está la precarización del trabajo docente con la posibilidad de enfermedad del mismo. Sin embargo, es posible que el elemento vivo del humano sea rescatado y que, por este motivo, la subjetividad docente sea construida de modo que se ejercite el trabajo creativo. Este artículo tiene como objetivo discutir de qué modo se da el arduo, pero posible, proceso de construcción de la subjetividad del profesor universitario en tiempos de la industria académica.

Palabras clave: Trabajo Docente. Universidad. Subjetividad. Sociabilidad.

\section{Introdução}

Compreender a docência não é algo simples! Que características precisa ter um bom professor? O que significa e que dimensões têm o trabalho docente? Este artigo, constituindo-se como um ensaio teórico, tem o objetivo de compreender como se constitui a subjetividade dos professores universitários diante do atual processo de industrialização acadêmica, isto é, a partir de um cenário em que o bom professor é 
aquele que mais produz, que mais escreve artigos, que tem mais participações em bancas de qualificação e defesa etc. Dito de outro modo, o bom professor de hoje é o docente produtivo. Para alcançar tal objetivo, adota-se uma metodologia expositiva e de estudo teórico, debruçada sobre bibliografia diversa que percorre os estudos acerca do sofrimento docente, passando pelos compêndios da Teoria Crítica.

A docência universitária parece ter entrado de vez na corrida da produtividade por meio da competitividade desenfreada e, por vezes, inescrupulosa. Basta observar a ferrenha luta de um docente para conseguir manter-se vinculado a programas de pósgraduação. Faz-se imprescindível, entre outras obrigações, uma publicação mínima anual de um dado número de artigos em periódicos bem avaliados para que sua permanência seja assegurada. Ora, trata-se de algo irônico, quiçá sarcástico, mas é possível dizer que a qualidade do trabalho do professor é, hoje, medida pela quantidade daquilo que produz.

\title{
20 trabalho docente precarizado: a universidade se tornando indústria
}

\begin{abstract}
Pane no sistema, alguém me desconfigurou. Aonde estão meus olhos de robô? Eu não sabia, eu não tinha percebido. Eu sempre achei que era vivo. Parafuso e fluido em lugar de articulação. Até achava que aqui batia um coração. Nada é orgânico, é tudo programado. E eu achando que tinha me libertado. Mas lá vêm eles novamente e eu sei o que vão fazer: reinstalar o sistema. ${ }^{2}$
\end{abstract}

Ela tem que acordar, preparar o café da manhã, levar as crianças até a escola e seguir para o trabalho. Entra no campus da universidade e segue para seu departamento. Depois, entra na sua sala. Lá, se dá conta do trabalho do dia (não que ela tenha se esquecido disso tudo durante a noite passada): tem que finalizar dois artigos e submetê-los ainda hoje, tem, também, que corrigir os trabalhos dos alunos da pós-graduação e colocar suas notas no sistema. Não pode se esquecer de preparar a aula da semana que vem para a graduação. Um pouco estressada, ela sai para tomar uma xícara de café. Precisa se manter acordada, mas isso já não é um problema. À noite, o sono teima em não vir de tantas preocupações que rodeiam sua mente.

\footnotetext{
${ }^{2}$ Admirável Chip Novo. Composição de Pitty.
} 
O telefone toca e ela recebe uma mensagem avisando que haverá uma reunião extraordinária do departamento. Problemas à vista!, pensa, e se levanta para ir em direção à sala de reuniões. Nas mãos carrega três ou quatro artigos de orientandos seus. São trabalhos que precisam ser corrigidos para que possam ser submetidos a algum periódico bem qualificado. Caso contrário, o currículo sofrerá com a ausência de publicação variada e recente. Também leva o celular e o netbook, pois pensa que talvez dê tempo de checar seu e-mail e atualizar seu Lattes. No bolso estão os remédios para dor nas costas, dor de cabeça e o ansiolítico. Terminado o dia de trabalho na universidade, ela segue para a escola e pega os filhos. Mal consegue ouvir o que eles vão contando dentro do carro. Sua cabeça está atolada de tanto trabalho. No banco do carona, trabalhos acadêmicos empilhados em meio a livros e artigos. Há uma tese que tem que ser lida para a banca do dia seguinte e ela ainda tem que preparar a janta. O desespero toma conta e ela tem até vontade de chorar só de pensar que ainda é segunda-feira.

Produção em série? Alguma lista de afazeres diários de uma máquina? Não, simplesmente se trata do que deve fazer uma professora universitária em seu dia-adia. Pode até parecer, mas não se trata de ficção. O cenário descrito acima reflete apenas uma realidade que vem tomando conta da vida de professores universitários de todo o Brasil. Tais exigências - entre muitas outras - se tornam parte da vida daqueles que desejam se destacar na carreira como docente universitário.

Desde o início da vida acadêmica, a publicação de artigos, resumos, a escrita de livros, as defesas em massa de mestrados e doutorados, a orientação de inúmeras iniciações científicas passam a ser pré-requisitos básicos para que um professor possa ser, então, chamado de pesquisador. Título caro nos dois sentidos da palavra: caro por ser fonte de importância e prestígio social em uma profissão tão desvalorizada pela sociedade como um todo. Caro por custar ao profissional em questão sua vida social, seu tempo livre e, muitas vezes, sua saúde. Ora, o adoecimento do professorado universitário já é uma constante e vem sendo estudado a fundo por Silva e Silva Júnior (2010; 2011) e Silva (2012). Bem, "uns se dopam para permanecer na corrida, outros se medicam para cuidar de suas feridas, e todos vivem com ansiedade e medo" (GAULEJAC, 2007, p.232). 
Trata-se exatamente do que ilustram as figuras 1 e 2, disponíveis no perfil intitulado "Pós-Graduando" de uma rede social. É comum que se encontre na página postagens de tirinhas e charges criticando, muitas vezes por intermédio de metáforas e ironias, o sistema de produção em série visto na academia e que se estende também aos estudantes, sobretudo aos pós-graduandos.

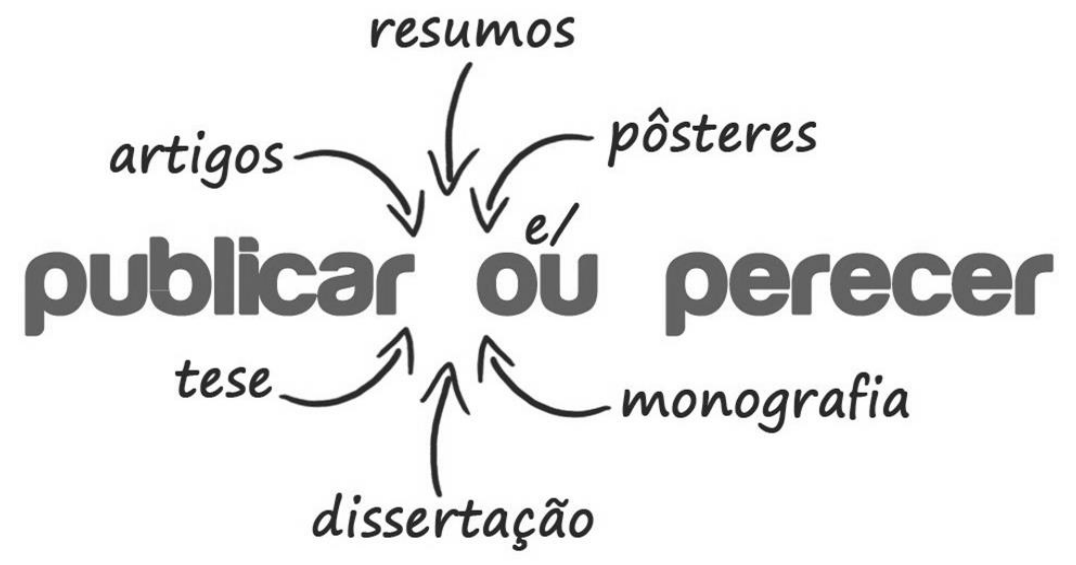

Figura 1- Esquema intitulado A lei da selva na pós-graduação, mostrando a necessidade de publicações constantes para estudantes de pós-graduação Fonte: <https://www.facebook.com/blogposgraduando>

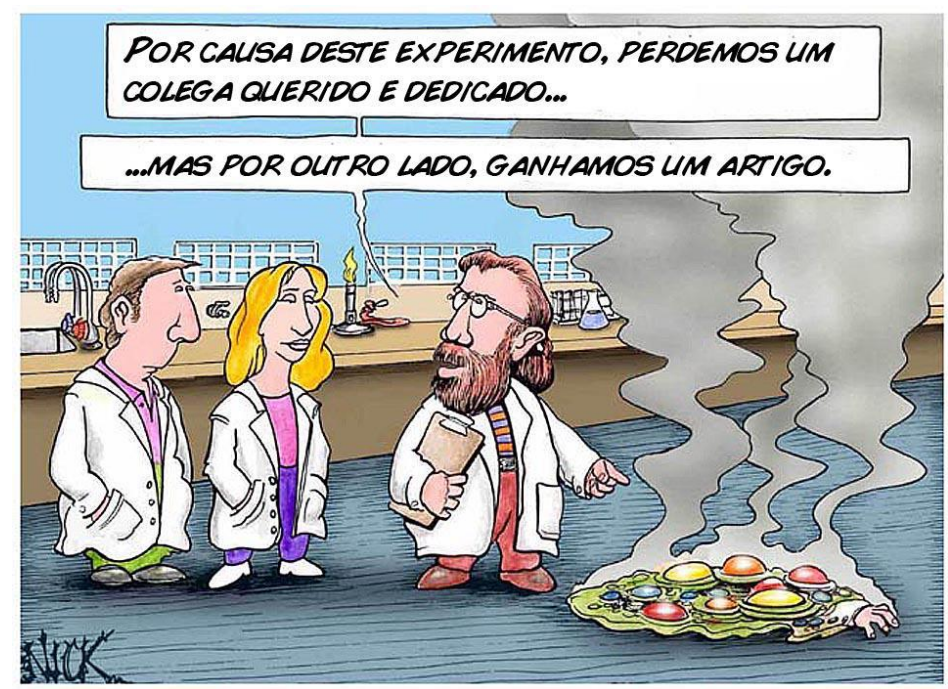

Figura 2 - Charge ironizando a publicação de artigos a qualquer custo Fonte: <https://www.facebook.com/blogposgraduando> 
Trata-se de um cenário pouco motivador, de fato, e é preciso compreender as causas (ou pelo menos algumas delas) de tal processo de crítica perda da saúde, entre elas, a competição extremada, a ansiedade e o estresse exacerbados, a vida acadêmica altamente exigente e ocupante de todo e qualquer tempo vago e a produção em série de artigos e demais publicações. Publicar ou não ser: eis a questão - poderia ser esse o lema das universidades brasileiras na atualidade.

Nesse sentido, o que fica embutido nesse processo de publicação a qualquer custo é justamente o empobrecimento da autorreflexão acerca do trabalho que vai sendo desenvolvido. Mills (2009) tece uma importante consideração sobre tal situação, direcionando-a ao caso dos cientistas sociais. Todavia, cabe tal comentário a todo e qualquer professor pesquisador que se encontre - por vezes, obrigado emaranhado no sistema e nas exigências das agências de fomento.

\begin{abstract}
Uma das piores coisas que acontecem com cientistas sociais é que só sentem necessidade de escrever sobre seus "planos" numa única ocasião: quando vão pedir dinheiro para uma pesquisa específica, ou "um projeto". É na forma de um pedido de recursos que se faz a maior parte do "planejamento", ou pelo menos se escreve cuidadosamente sobre ele. Embora esta seja a prática usual, penso que é muito ruim: está fadada em algum grau a ser publicidade de vendedor e, dadas as expectativas prevalecentes, resultará muito provavelmente em pretensões meticulosas; é provável que o projeto seja "apresentado" de uma maneira arbitrariamente "arredondada" muito antes do que deveria; é muitas vezes algo maquinado, destinado a obter o dinheiro para propósitos velados, por valiosos que sejam, bem como para a pesquisa apresentada (MILLS, 2009, p. 24).
\end{abstract}

Nesse âmbito, o trabalho docente não deixa de ser alienado, uma vez que o professor "não se afirma no trabalho, mas nega-se a si mesmo, não se sente bem, mas infeliz, não desenvolve livremente as energias físicas e mentais, mas esgota-se fisicamente e arruína o espírito" (MARX, 1989, p. 162). Ora, chega-se ao momento em que os professores veem a escrita de artigos como um fim em si mesmo. Não há mais aquela preocupação em escrever os resultados e as considerações de uma pesquisa para tornar públicos tais dados, ligando e conectando comunidade e universidade.

Diante do cenário de exigências como produção em série, o docente, muitas vezes, escreve por escrever, produz por produzir sem nem mesmo ter se aprofundado na temática abordada do modo como gostaria ou poderia. Servo de suas produções, assim como o trabalhador se torna servo do objeto que produz, o docente entra em uma crítica situação na qual "o objeto capacita-o para existir, primeiramente como 
trabalhador, em seguida, como sujeito físico. A culminação de tal servidão é que ele só pode manter-se como sujeito físico enquanto trabalhador e só é trabalhador enquanto sujeito físico", afirma Marx (1989, p. 160, grifos originais do autor).

Nesse sentido, poder-se-ia questionar se a universidade, de modo geral, não está se tornando uma Indústria Acadêmica. Bem, trazendo à discussão aspectos centrais da chamada Indústria Cultural - como a massificação e a padronização da produção cultural, por exemplo - já se tem elementos que apresentam possibilidades de comparação. Na Indústria Cultural, os produtos são pensados antes mesmo de sua produção propriamente dita. Para ser concretamente produzido, investiga-se, antes, seu possível e provável público consumidor, bem como as características que os tornem sucesso de vendas (isto é, facilmente absorvíveis e comercializáveis).

A Indústria Acadêmica não difere tanto desse cenário. Dependentes e - podese dizer - determinados pelas agências de fomento e pela grandiosidade de seus currículos (que privilegiam invariavelmente a quantidade no lugar da qualidade), os professores universitários mergulham na lógica de uma verdadeira indústria. Se antes sua pesquisa era pensada de acordo com uma pergunta a ser respondida, com uma necessidade a ser sanada, hoje, são muitas as temáticas que se ocupam com aquilo que, possivelmente, conseguirá o apoio financeiro das agências de fomento. Os docentes vivem uma lógica subversiva: por precisar do recurso financeiro e para se manter em posição favorável ao alcance de tais fomentos, acabam se submetendo, muitas vezes contra sua vontade, aos mandos e desmandos do sistema. Obviamente tal situação tem, também, íntima relação com a remuneração deficiente do professorado, a qual sempre necessita de complementos.

A dificuldade de se administrar/conciliar a vida acadêmica com as relações pessoais também tem muito a dizer. Não há mais divisão entre trabalho e lazer, fato este que aproxima, mais uma vez, a docência universitária de uma Indústria Acadêmica. Na Indústria Cultural, lazer e trabalho se confundem, ou seja, a lógica da produção do tempo livre está muito próxima à lógica de produção industrial e econômica. Nas palavras de Gaulejac (2007, p.216), “o contexto suscita uma pressão contínua, um sentimento de jamais fazer o suficiente, uma angústia de não estar à altura daquilo que a empresa exige". Para Adorno e Horkheimer (1986), tal situação 
caracteriza a fuga da possibilidade de resistência e de crítica à realidade, levando à reprodução da mesma lógica padronizada do trabalho nos momentos de lazer.

Há outra característica típica da vida agitada e complexa do professor pesquisador: a já mencionada competição. Silva $(2012$, p.11) afirma que "os processos de desestruturação das relações sociais e de degradação da vida e da solidariedade são típicos da cultura da performance e da eficácia e podem ser relacionados ao adoecimento e ao assédio moral". Em uma luta ferrenha para ser notado e diferenciado dos demais de alguma forma, o docente acaba por adotar estratégias de visibilidade.

Como pontuam Silva e Silva Júnior (2011, p.68), tal processo competitivo, nas palavras de um professor entrevistado, "se caracterizaria como 'um espaço de relações de poder', no qual os professores buscariam uma 'afirmação' que favoreceria 'essa política da produtividade'". O narcisismo de Freud se coloca aqui nitidamente, conceito este que pode ser entendido como uma autossuficiência, isto é, "o complemento libidinal do egoísmo do instinto de autoconservação [...]" (FREUD, 2010, p. 14-15). O conceito de ser é ser percebido de Türcke (2010) - utilizado no contexto da Indústria Cultural - também cabe nesse enredo, bem como a pressão para emitir, a compulsão à emissão e a chamada mímesis compulsiva:

A compulsão à ocupação é especificada em uma compulsão à emissão. Ela transforma-se, entretanto, em uma forma vital de expressão. Emitir quer dizer tornar-se percebido: ser. Não emitir é equivalente a não ser - não apenas sentir o horror vacui da ociosidade, mas ser tomado da sensação de simplesmente não existir. Não mais apenas: "há um vácuo em mim", porém "sou um vácuo" - de forma alguma aí (TÜRCKE, 2010, p. 44-45).

Mesmo sabendo que estão fazendo parte de um sistema nocivamente manipulativo e alienante, os docentes - assim como os consumidores dos produtos da Indústria Cultural - acabam por se inscrever e responder ativamente a essa lógica. Daí advém a comparação com a mímesis compulsiva típica do processo de massificação e enquadramento causado pela Indústria da Cultura: ocorre um comportamento de identificação cega.

Já os novos doutores têm sido levados a se associarem com mais rapidez e
menos resistência ao sistema que tem orientado o trabalho acadêmico. Eles
acabam por absorver de forma mais concreta o ideário capitalista do
espetáculo na docência, através da corrida ainda mais frenética por
reconhecimento através do excesso de participação em eventos e da
publicação em cadeia sobre vários assuntos, não raras vezes sem poderem 
dar a continuidade e a profundidade necessária às próprias pesquisas. Afinal, o tempo urge, e o Lattes também (FIDALGO, 2010, p. 163).

Surge, então, uma questão chave: como se constrói a subjetividade docente em um contexto de industrialização da academia e perante a alienação do trabalho do professor universitário?

\section{A subjetividade forjada e a sociabilidade produtiva}

Sempre precisei de um pouco de atenção. Acho que não sei quem sou. Só sei do que não gosto. E destes dias tão estranhos fica a poeira se escondendo pelos cantos. Esse é o nosso mundo: o que é demais nunca é o bastante e a primeira vez é sempre a última chance. Ninguém vê onde chegamos: os assassinos estão livres, nós não estamos. ${ }^{3}$

Nós não estamos livres. É preciso concordar com a letra da canção de Renato Russo. Apesar de levados a crer em tal liberdade, isso não passa de um funesto processo dissimulado de manipulação do sistema sobre os indivíduos. Acreditando ser parte ativa da construção da sociedade, o homem se aquieta e não se torna mais algo perigoso para o status quo vigente. Isso ocorre nitidamente dentro de fábricas. Com os slogans fortemente divulgados de que os funcionários devem vestir a camisa e abraçar a causa da empresa, formando-se, assim, uma grande família, a alienação se impõe de maneira concisa. Já alheios ao que produzem, estranhando o objeto produzido, agora também se tornam rebanho obediente de uma ordem que manipula, dissimula e perpetua as diferenças e os abismos sociais.

Na universidade, porém, poder-se-ia, com razão, imaginar que o contrário impera: seria este o lugar da crítica, da reflexão e do questionamento constantes acerca das diferenças sociais e de suas causas e consequências, entre outras temáticas. Seria a universidade o lócus de resistência à manipulação. Ora, tal afirmação faz sentido apenas em seu teor teórico e ideal. Sim, a universidade deveria estar empenhada em desnaturalizar a alienação daquele funcionário do mês da empresa $x$, porém, o que marca os campi universitários públicos brasileiros é um processo de alienação não menos latente que na fábrica e na empresa.

\footnotetext{
${ }^{3}$ Teatro dos Vampiros. Composição de Renato Russo.
} 


\begin{abstract}
A Universidade tem sido palco a sediar espetáculos diários, respaldados em bases econômicas e repercutindo fortemente sob a forma de ações estatais no interior da academia, através de representantes como a CAPES, o CNPq, as agências de fomento estaduais, dentre outros. Todos estes agentes conferem um caráter de competitividade ao professor na pós-graduação, que tenta atender aos scripts que norteiam o trabalho no seio da academia e cerceiam sua autonomia, não somente de agir frente às demandas colocadas, mas frequentemente, até mesmo de questionar, de compreender como as políticas no meio se processam (FIDALGO, 2010, p. 161-162).
\end{abstract}

Se lá, o funcionário se esforça para ser o destaque do mês, em um misto de alienação e narcisismo, na universidade o docente se dedica (com dedicação exclusiva, diga-se de passagem) a ser o destaque do departamento, sobretudo devido a seus títulos, publicações, qualificações Lattes etc., em um processo não menos alienado e narcisista. É desse enredo que emerge a questão posta no final do item anterior: como se constrói a subjetividade do professor universitário defronte a esse cenário?

Bem, primeiramente, é preciso compreender o que seria essa subjetividade. Nas palavras de Doray (1989, p.85), é o "conjunto dos processos pelos quais o indivíduo, em estreito contato com as estruturas simbólicas da cultura humana, tenta assumir e abrir um acesso à forma genérica de seu ser". Desse modo, algo já se faz explícito: não há subjetividade sem sociabilidade. Em outras palavras, subjetividade e sociabilidade são irredutíveis e indissociáveis.

Desse modo, sendo a subjetividade socialmente produzida e as instituições mediadoras da construção de valores, ocorre o chamado sequestro da subjetividade ao longo das ações e do cotidiano, enfim, das práticas sociais. Ocorre que, diante de um cenário de alienação do trabalho docente universitário, o que se tem, em geral, são as subjetividades forjadas.

Trazendo, novamente, o exemplo do trabalhador que se esforça para ser o funcionário do mês, tem-se o perigo dessa subjetividade forjada, sobretudo quando atrelada a uma sociabilidade produtiva. Não ocorre, na situação referida, a sublimação dos impulsos do trabalhador, algo que deveria ocorrer no trabalho (o trabalho sublimatório), mas, sim, uma repressão (ou dessublimação repressiva), por meio da cooptação desse trabalhador. Segundo Gernet e Dejours (2011):

Tais práticas, que apelam para o envolvimento dos trabalhadores (mediante a identificação de suas qualidades, de sua apresentação pessoal, de suas redes de colaboração...), equivaleriam na verdade a práticas que negam a 
subjetividade dos homens e das mulheres que trabalham (GERNET; DEJOURS, 2011, p. 67).

O mesmo se dá no caso do professor docente que produz como um fim em si mesmo e que, no entanto, é cooptado para que isso ocorra. O trabalho perde sua dimensão sublimatória ${ }^{4}$ e se torna usurpador de subjetividades. Dá-se um verdadeiro "sequestro de subjetividade", como assinalam Silva e Silva Júnior (2011, p. 66, 68), autores estes que também salientam que "a construção do coletivo no interior de uma gestão heterônoma e de relações de trabalho calcadas no individualismo e competitividade é significativamente dificultada no cotidiano do trabalho do professor". Ora, a partir do momento em que deixa de imperar a solidariedade e o reconhecimento coletivo, passa a prevalecer uma competitividade nociva - pois pautada na produtividade como fim em si mesma - ocasionando, por conseguinte, a perda das potencialidades emancipadoras do coletivo. Nesse contexto:

\begin{abstract}
O coletivo de trabalho não é mais portador de laços estáveis. Não funda mais um sentimento de pertença na duração. Não é mais o suporte essencial da identidade social: as identidades profissionais desaparecem, as pertenças a um "corpo" profissional se tornam obsoletas, a mobilidade não permite mais se instalar duravelmente em um grupo de trabalho. $O$ coletivo não realiza mais sua função de mediação entre o indivíduo e a empresa. Em caso de conflito, ele não é mais o lugar em que se decidem as formas de resistência, as estratégias de luta, a elaboração de reivindicações. Ele não representa mais um elemento central de solidariedade e de proteção. As injunções de flexibilidade, como os sistemas de avaliação individualizados, reforçam a competição e não tanto a colaboração (GAULEJAC, 2007, p. 151).
\end{abstract}

\title{
4 Trabalho criativo e subjetividade resgatada: o elemento vivo do humano
}

\begin{abstract}
O perigo existe, faz parte do jogo, mas não fique triste que viver é fogo. Veja se resiste, comece de novo. Ao cruzar a rua você está arriscando, pode estar na lua, pode estar amando. Passa um caminhão, cruza uma perua. O cara tá na dele, você tá na sua. Mas atravesse a rua sem medo. ${ }^{5}$
\end{abstract}

A partir de tal devastador cenário com relação à situação do professor do ensino superior, pode-se pensar que não há saída. Ora, tendo tido forjada sua identidade, o educador perde sua capacidade de ser essencialmente humano e sua

\footnotetext{
${ }^{4}$ A sublimação, nos termos freudianos, pode ser caracterizada pelo processo no qual as energias pulsionais seriam canalizadas para um fim socialmente aceito. Como exemplo, têm-se as pulsões agressivas e eróticas sublimadas para o trabalho.

${ }^{5}$ Sem Medo. Composição de Toquinho e Vinicius de Moraes.
} 
autonomia se dissipa de forma irreversível. Correto? Felizmente, não! Para Lukács (2012) a subjetividade (conceito central em sua obra) é, ao mesmo tempo, humanizada e coisificada. O elemento vivo do humano nunca deixará de ter uma dimensão ativa. De acordo com Silva e Silva Júnior (2010, p.237), é possível "afirmar que, na praxis educacional e no mundo do trabalho, não se apaga o sujeito histórico e ontológico cuja prática jamais será plenamente cooptada ou subsumida pela lógica pragmático-mercantil do capital".

Ora, o homem reage e, por isso, jamais ficará preso a uma dimensão meramente passiva. O trabalho do professor - ao se enxergar e se compreender alienado e fonte de estranhamento - pode possibilitar uma reflexão sobre tal alienação, emergindo, por decorrência, práticas diferentes. Trata-se de:

\footnotetext{
Conciliar o fato (vida) com a necessidade (produzir) para viver, e não apenas sobreviver. E aqui, a relação com o outro é essencial, a relação entre vida e produção é coletiva, não se vive só e nem se produz sozinho tudo o que é preciso para viver. Portanto, é mister pensar se a docência, ao ser pressionada por tantos lados, não está tomando uma rota inversa que a cerceia cada vez mais de assumir novas ações que reconfigurem o desenvolvimento do seu trabalho ao seu favor (FIDALGO, 2010, p. 188).
}

Retomando-se o conceito de identidade, pode-se recorrer a Ciampa (1984). Bem, a identidade não é uma essência, não é algo imutável e estático. Para o autor, inclusive, trata-se, pelo contrário, de uma totalidade que se constrói na história e, por isso, é contraditória e múltipla. É exatamente nesse ponto que se coloca a possibilidade de se resgatar a subjetividade do professor universitário, então forjada. A identidade do indivíduo não está engessada, mas sim em constante mutação. "Para a psicodinâmica do trabalho, a identidade é a 'armadura da saúde mental', ela não está jamais definitivamente estabilizada e permanece incerta, incompleta" (GERNET; DEJOURS, 2011, p. 66).

Nesse sentido, a instituição não deixará de ser local das articulações e desarticulações entre o socialmente prescrito e a subjetividade (NASCIUTTI, 2007). Ocorre que os processos sociais não se limitam à dimensão individual e indivíduo nenhum se torna completamente submisso aos determinantes objetivos da realidade social. Na universidade, por exemplo, há ferrenhos conflitos entre papéis préestabelecidos e subjetividades. Pode-se, inclusive, dizer que o indivíduo passa muito perto de se tornar objeto, mas, em hipótese alguma, deixa de ser sujeito. O conflito 
entre o prescritivo e o normativo, entre o normativo e o subjetivo não deixa de ocorrer, sendo a instituição um espaço essencialmente contraditório. Contudo, há possibilidades latentes de ser a instituição também um espaço criador e transformador, muito embora não deixe de ser contraditório (NASCIUTTI, 2007).

Nesse contexto, surge aquilo que Dejours (2004a; 2004b) chamou de transgressão do prescrito, ou seja, para o autor haveria a possibilidade de transformação da organização do trabalho de forma que, agindo para além do prescrito, os trabalhadores estariam significando sua atividade e, mais do que isso, mobilizando sua subjetividade. Dito de outra forma, aquela defesa que se impunha como consequência do sofrimento e que reverberava em uma adaptação se torna, agora, outra defesa. Trata-se de uma defesa pela sublimação, na qual a fuga do adoecimento e do sofrimento está exatamente no coletivo, isto é, na cooperação e no reconhecimento entre os trabalhadores, reconhecimento este de base coletiva, que é estruturante, muito diferente daquela busca individual e competitiva por uma visibilidade narcisista e pela afirmação de si mesmo.

Mas o que propõe Dejours? - pode-se perguntar. Ora, para o autor, a defesa pela sublimação promoveria, por conseguinte, um trabalho criativo, com possibilidades, por exemplo, de liberdade do modo operatório. Nas palavras de Dejours (2004b, p.155), “o trabalho, certamente, é o único mediador eficiente possível do desejo no campo social, ou, em outros termos, seria o intermediário insubstituível entre o inconsciente e o campo social".

As chamadas trapaças (que carregam o sentido de uma insubordinação criativa e legitimada de modo coletivo) - ou meio de se "fazer com que a defesa seja percebida como desejo", como salienta Dejours (2004b p. 153) - também surgem nesse enredo: a partir do momento em que algo prescrito se coloca como empecilho para uma atividade criativa, os trabalhadores encontram formas de burlar as regras e colocar sua inventividade em ação. Mas essa trapaça a que Dejours (2004b) se refere não pode ser entendida como algo doloso e, sim, como uma estratégia que tem de ser legitimada a partir da construção do espaço público da palavra, chegando-se, por fim, ao reconhecimento, uma vez que - nas palavras de Gernet e Dejours (2011, p.67) "quem foi reconhecido pela contribuição que trouxe à organização por seu trabalho 
pode, eventualmente, voltar esse reconhecimento de seu saber-fazer para o registro de sua identidade".

No entanto, se equivoca fortemente quem acredita que é possível, mesmo por meio do trabalho sublimatório, uma relação exclusiva de prazer entre trabalhador e trabalho. É preciso compreender que a organização prescrita do trabalho é a base para que as subversões aconteçam, ou seja, sem o conjunto normativo das organizações, as trapaças não conseguem se realizar. Ocorre, nesse sentido, uma dialética entre prazer e sofrimento, visto que o prazer do trabalho criativo não está de modo algum separado do esforço e do sofrimento, fato este que permite a dimensão desejante de superação do que já existe. E é exatamente neste ponto que está o enigma do trabalho: trata-se de uma atividade em que o trabalhador está sempre buscando ir para além do prescrito, encontrando-se com a dimensão criativa, como acentua Dejours (2004a).

Desse modo, é possível, novamente, trazer à tona o professor universitário e os dilemas de um cenário em que a universidade vai se transformando, gradualmente, em uma Indústria Acadêmica. Como fica a subjetividade de um docente que se sente sequestrado pelo sistema, explorado pelo prescrito? Ora, nenhum trabalho humano perde por inteiro seu caráter criativo! O professor universitário, apesar de estar em meio a uma crise de identidade, não deixa de colocar em cada atividade que exerce um pouco de sua criação, uma dose de sua inventividade. Ocorre que é necessário para não dizer imprescindível - que o professor tome consciência da situação de exploração em que está inserido, fugindo, para tanto, da defesa pela adaptação, uma vez que, "ao permitir o acesso à adaptação aos riscos, as defesas impedem, parcialmente ao menos, a tomada de consciência das relações de exploração" (DEJOURS, 2004b, p.145). Em resumo:

No universo gerencialista, a subjetividade é mobilizada sobre objetivos, resultados, critérios de sucesso, que tendem a excluir tudo aquilo que não é útil ou rentável. $\mathrm{O}$ valor comercial tende a se impor a qualquer outra consideração. O sentido do ato é considerado pela empresa em função daquilo que ele fornece. Os outros sistemas de sentido são postos de lado. Mas, como eles não desaparecem completamente e apesar das pressões para que os agentes deem adesão ao sentido prescrito pela empresa, as tensões são vivas (GAULEJAC, 2007, p. 154).

O reconhecimento seria, nesse enredo, elemento essencial na transformação do sofrimento em prazer no trabalho. Um artigo publicado em uma revista que passa por um processo de reconhecimento e é elogiado pelos pares, por exemplo, seria um 
modo de fazer com que o trabalho - sem ter perdido por completo sua dimensão de sofrimento, a qual é a ele inerente - fosse reconhecido, mobilizando de forma prazerosa a subjetividade docente. Esse reconhecimento, vale ressaltar, precisa ser entendido para além de seu caráter de prestígio, mas, sim, como uma "relação estreita estabelecida entre o trabalho e a experiência do corpo" (GERNET; DEJOURS, 2011, p.67).

Em suma, jamais será possível a transformação completa de um indivíduo em objeto. Felizmente, o elemento humano do vivo não permite que tal nefasto processo ocorra. E, nesse sentido, é essencial compreender que há possibilidades de escapar à lógica do sistema que impera, sobretudo quando se tem consciência de tal chance. Afinal, segundo Gaulejac (2007), que nos inspira a virtuosas trapaças:

\footnotetext{
Cada agente conserva seu "sentido para si mesmo". Se ele parece aderir ao que o gerenciamento dele espera, essa adesão será apenas de fachada. A partir do momento que puder, ele denunciará a inanidade de um sistema que perverte o 'bom sentido' ou o que ele considera como contrassenso de seus próprios valores (GAULEJAC, 2007, p. 154).
}

\section{Referências}

ADORNO, T. W.; HORKHEIMER, M. Dialética do esclarecimento: fragmentos filosóficos. Trad. de Guido Antonio de Almeida. Rio de Janeiro: Jorge Zahar, 1986.

CIAMPA, A. da C. Identidade. In: Psicologia Social: o homem em movimento. São Paulo: Brasiliense, 1984.

DEJOURS, C. O trabalho como enigma. In: LANCMAN, S.; SZNELWAR, L. (Orgs.). Christophe Dejours: da psicopatologia à psicodinâmica do trabalho. Rio de Janeiro: Fiocruz, 2004a. p.127-140.

DEJOURS, C. Sofrimento e prazer no trabalho: a abordagem pela psicopatologia do trabalho. In: LANCMAN, S.; SZNELWAR, L. (Orgs.). Christophe Dejours: da psicopatologia à psicodinâmica do trabalho. Rio de Janeiro: Fiocruz, 2004b. p. 141-156.

DORAY, B. Da produção à subjetividade: referência para uma dialética das formas. In: SILVEIRA, P.; DORAY, B. (Orgs.). Elementos para uma teoria marxista da subjetividade. São Paulo: Vértice, 1989. p. 77-108. 
FIDALGO, N. L. R. A espetacularização do trabalho docente universitário: dilemas entre produzir e viver e viver para produzir. 2010. 200 f. Tese (Doutorado em Educação) - Universidade Federal de Minas Gerais. Belo Horizonte.

FREUD, S. Introdução ao narcisismo, ensaios de metapsicologia e outros textos (19141916). Trad. de Paulo César de Souza. São Paulo: Companhia das Letras, 2010.

GAULEJAC, V. de. Gestão como doença social: ideologia, poder gerencialista e fragmentação social. Trad. de Ivo Storniolo. Aparecida: Ideias \& Letras, 2007.

GERNET, I.; DEJOURS, C. Avaliação do trabalho e reconhecimento. In: BENDASSOLLI, P. F.; SOBOLL, L. A. P. (Orgs.). Clínicas do trabalho: novas perspectivas para compreensão do trabalho na atualidade. São Paulo: Atlas, 2011. p. 61-70.

LUKÁCS, G. Trabalho. In: Ontologia do Ser Social. Tradução de Carlos Nelson Coutinho, Mario Duayer, Nélio Schneider. São Paulo: Boitempo, 2012. p. 5-95.

MARX, K. O trabalho alienado. In: . Manuscritos econômico-filosóficos. Lisboa: Edições 70, 1989. p. 157-172.

MILLS, C. W. Sobre o artesanato intelectual. In: Sobre o artesanato intelectual e outros ensaios. Trad. de Maria Luiza Borges. Rio de Janeiro: Jorge Zahar, 2009. p. 2158.

NASCIUTTI, J. C. R. A instituição como via de acesso à comunidade. In: CAMPOS, R. H. de F. (Org.). Psicologia social comunitária: da solidariedade à autonomia. Petrópolis: Vozes, 2007. p. 100-126.

SILVA, E. P.; SILVA JÚNIOR, J. dos R. Estranhamento e desumanização nas relações de trabalho na instituição universitária pública. Revista HISTEDBR On-line, Campinas, $\mathrm{n}$. especial, p. 223-238, ago. 2010.

SILVA, E.P.; SILVA JÚNIOR, J. dos R. Da avaliação heterônoma da pós-graduação à desumanização das relações de trabalho na instituição universitária pública. In: ROTHEN, J. C.; BARREYRO, G. B. (Orgs.). Avaliação da educação: diferentes abordagens críticas. São Paulo: Xamã, 2011. p. 55-73. 
SILVA, E. P. Por uma leitura sui generis do sofrimento e prazer no trabalho intensificado do professor na universidade pública brasileira: articulações entre a teoria marxista da subjetividade, Psicossociologia e Psicodinâmica do Trabalho. Simpósio apresentado no Congresso Internacional de Psicologia do Trabalho e das Organizações. Universidade Católica Portuguesa. Centro Regional de Braga. Faculdade de Filosofia. 2012. (Mimeo).

TÜRCKE, C. Sociedade excitada: filosofia da sensação. Trad. de Antônio Álvaro Soares Zuin, Fabio Durão, Francisco Fontanella e Mario Frungillo. Campinas: Editora da Unicamp, 2010.

Enviado em Janeiro/2013

Aprovado em Abril/2014 